JURNAL PANGAN DAN GIZI 9 (1): 27-38, April 2019

ISSN 2086-6429 (Online)

Tersedia online di http://jurnal.unimus.ac.id/index.php/JPDG

\title{
TINGKAT KEKERUHAN, KADAR VITAMIN C DAN AKTIVITAS ANTIOKSIDAN INFUSED WATER LEMON DENGAN VARIASI SUHU DAN LAMA PERENDAMAN
}

\section{Turbidity, Vitamin C and Antioxidant Activity of Lemon Infused Water With Variation in Temperature and Soaking Time.}

\author{
Indah Trisnawati, Wikanastri Hersoelistyorini, Nurhidajah
}

Program Studi Teknologi Pangan, Fakultas Keperawatan dan Kesehatan

Universitas Muhammadiyah Semarang

Korespondensi : indahtrisnawati13@gmail.com

\begin{abstract}
Lemon is a fruit that is rich in vitamin $C$. The processing of lemon as an infused water is one way to get optimal benefits from lemon. Lemon infused water is treated by soaking it in water for several hours. The temperature and soaking time are thought to influence the physical and chemical characteristics of lemon infused water. This study aims to determine the level of turbidity, vitamin $C$ and antioxidant activity of lemon infused water. This study used a completely randomized design of two factors, with two differences in temperature (refrigerator temperature and room temperature) and five differences in soaking time (1, 2, 3, 4, 5 hours) and then analyzed turbidity levels, vitamin $C$ levels and antioxidant activity. Observation data were analyzed using Two Way Anova. The results showed turbidity, vitamin $C$, and antioxidant activity at room temperature were higher than the refrigerator temperature and the longer soaking the turbidity level, vitamin $C$, and antioxidant activity were also as high as possible. The results of the analysis of variance showed that there were effects of temperature and soaking time on the level of turbidity and vitamin $C$ of lemon infused water but there was no effect of soaking time on antioxidant activity. Soaking time at room temperature for 1 hour or at refrigerator temperature for 4 hours is the best time to get optimum vitamin $C$ and antioxidant activity.
\end{abstract}

Keywords: lemon, lemon infused water, turbidity, vitamin $C$, antioxidant activity

\section{PENDAHULUAN}

Infused water atau spa water adalah

air yang ditambah dengan potongan buah-

buahan dan didiamkan selama beberapa jam sampai sari buahnya keluar, lalu siap dikonsumsi, sehingga memberi cita rasa dan manfaat untuk kesehatan. Air yang diberi potongan buah ini akan terasa segar dan 
beraroma khas, tidak terasa manis seperti jus atau sari buah karena tanpa tambahan zat aditif (Haitami et al., 2017). Infused water dapat digunakan sebagai salah satu alternatif bagi mereka yang tidak atau kurang suka buah dan tidak sempat mengkonsumsi buah. Selain itu, infused water juga dapat mendorong selera seseorang untuk mengkonsumsi air lebih banyak (Soraya, 2014). Salah satu infused water yang dikenal oleh masyarakat adalah infused water dari buah lemon.

Jeruk lemon merupakan salah satu buah yang kaya akan vitamin C serta kandungan antioksidan yang bermanfaat bagi tubuh manusia. Jeruk lemon mengandung 3,7\% asam sitrat dan vitamin $\mathrm{C}$ 40-50 mg / $100 \mathrm{~g}$ (Kristanto, 2013). Walaupun memiliki banyak manfaat bagi tubuh, lemon mengandung asam sitrat dengan $\mathrm{pH}$ rendah yaitu 2,74 (Manner et al. 2006). Menurut Caranza (2012) dalam Kurniawati et al. (2014) makanan / minuman asam dibawah $\mathrm{pH}$ 5,5 dapat menyebabkan erosi serta kekasaran pada gigi. Selain itu $\mathrm{pH}$ rendah juga sensitif bagi pencernaan manusia khususnya lambung. Pengolahan lemon sebagai minuman infused water bisa menjadi salah satu alternatif untuk mengatasi keasaman pada buah lemon.

Prinsip pembuatan infused water yaitu dengan perendaman potongan buah didalam air. Sari dan bahan yang terkandung didalam buah akan terlarut ke dalam air sehingga bisa dirasakan manfaatnya ketika menikmati infused water. Bahan akan terlarut secara endoterm dimana memerlukan kalor untuk terjadinya reaksi (perpindahan bahan) (Anggraeni, 2011). Semakin tinggi suhu air maka perpindahan sari buah akan semakin cepat. Bahan yang berasal dari buah akan terlarut ke dalam air hingga homogen.

Infused water lemon dipercaya memiliki kandungan vitamin $\mathrm{C}$ yang bermanfaat bagi tubuh. Vitamin C 
merupakan salah satu jenis vitamin yang larut air dan berperan dalam menangkal berbagai penyakit. Peran vitamin $\mathrm{C}$ dalam menangkal berbagai penyakit yaitu sebagai zat antioksidan untuk menetralkan radikal bebas. Selain vitamin C, juga terdapat komponen lain yang juga berperan sebagai antioksidan pada buah lemon yaitu flavonoid dan total fenolik (Anagnostopoulou et al., 2006 dalam Krisnawan et al., 2017). Kadar total fenol pada buah lemon yaitu sebesar 110,25 mg GAE/100ml (Permata et al., 2018).

Infused water jeruk lemon umumnya diolah dengan perendaman lemon di dalam air selama beberapa jam. Perendaman ini membuat air putih menjadi lebih keruh daripada sebelum perendaman. Menurut Hefni (2003) dalam Romain (2014) kekeruhan diakibatkan oleh benda tercampur atau benda koloid di dalam air. Selain itu, perendaman juga membuat sifat kimia air putih semakin bertambah sesuai kandungan gizi buah yang direndam didalamnya. Penelitian Wassalwa (2016) menunjukkan bahwa perendaman kulit pisang dalam air (infused water kulit pisang) selama 120 menit mempunyai kandungan vitamin $\mathrm{C}$ dan aktivitas antioksidan lebih tinggi daripada perendaman selama 30 menit. Namun, pada suhu $45^{\circ} \mathrm{C}$ vitamin $\mathrm{C}$ dan aktivitas antioksidan infused water kulit pisang mengalami penurunan. Penelitian Sapei et al. (2013) juga menunjukkan degradasi vitamin C strawberry juice pada suhu $8^{\circ} \mathrm{C}$ lebih kecil daripada suhu $28^{\circ} \mathrm{C}$. Selain itu, penelitian Faramade (2007) menunjukkan bahwa kerusakan vitamin C sari buah jeruk pada suhu $7^{\circ} \mathrm{C}$ lebih kecil dibandingkan pada suhu $28^{\circ} \mathrm{C}$.

Suhu dan lama perendaman diduga juga berpengaruh terhadap kekeruhan, kadar vitamin $\mathrm{C}$ dan aktivitas antioksidan infused water jeruk lemon. Oleh sebab itu, perlu dilakukan penelitian tentang pengaruh suhu dan lama perendaman terhadap kekeruhan, 
kadar vitamin $\mathrm{C}$ dan aktivitas antioksidan infused water jeruk lemon. Tujuan penelitian adalah mengetahui pengaruh suhu dan lama perendaman terhadap kekeruhan, kadar vitamin $\mathrm{C}$ dan aktivitas antioksidan infused water jeruk lemon.

\section{BAHAN DAN METODE}

\section{Bahan}

Bahan utama dalam pembuatan infused water lemon yaitu lemon yang dibeli di ADA Bulu Semarang yang berwarna kuning, tidak rusak / berlubang, berat 80 100 gram, diameter $6-8 \mathrm{~cm}$ dan air mineral kemasan. Bahan kimia yang digunakan terdiri atas aquades, DPPH, metanol, asam askorbat, keras saring, amilum, $\mathrm{Na}_{2} \mathrm{~S}_{2} \mathrm{O}_{3}, \mathrm{KBrO}_{3} 0,01 \mathrm{~N}, \mathrm{H}_{2} \mathrm{SO}_{4}$ $0,01 \mathrm{~N}, \mathrm{KI} 10 \%$, Iodium $0,01 \mathrm{~N}$, larutan $\mathrm{HCl}$.

\section{Pemilihan Bahan Baku}

Bahan yang digunakan dalam penelitian ini adalah jeruk lemon yang berwarna kuning, tidak rusak atau berlubang, diameter dari $6-8 \mathrm{~cm}$, dengan berat antara $80-100$ gram

\section{Pembuatan Infused Water Lemon}

Buah lemon yang telah dipilih dicuci bersih, diiris membujur menjadi 8 bagian dan direndam dengan air putih sebanyak 200 ml dalam botol selai di suhu ruang dan refrigerator selama 1, 2, 3, 4 dan 5 jam selanjutnya dianalisa tingkat kekeruhan, vitamin $\mathrm{C}$, dan aktivitas antioksidan.

\section{Analisa Data}

Untuk mengetahui pengaruh variasi suhu dan lama perendaman terhadap tingkat kekeruhan, kadar vitamin $\mathrm{C}$ dan aktivitas antioksidan infused water lemon diakukan uji Two Way Anova dengan tingkat kepercayaan 95\%. Data hasil pengamatan diuji kenormalan data menggunakan Kolmogorov Smirnov kemudian dianalisis menggunakan Two Way Anova yang dilanjutkan dengan uji lanjut Tukey. 


\section{HASIL DAN PEMBAHASAN}

\section{Tingkat kekeruhan}

Kekeruhan pada infused water merupakan bahan yang terlarut di dalam air yang berasal dari buah yang digunakan. Hasil penelitian ini yaitu air yang diberi potongan buah (infused water) lemon menunjukkan semakin lama perendaman maka tingkat kekeruhan akan semakin tinggi. Hal ini diduga karena semakin lama perendaman maka semakin banyak bahan yang terlarut sehingga mempengaruhi kekeruhan air tersebut.

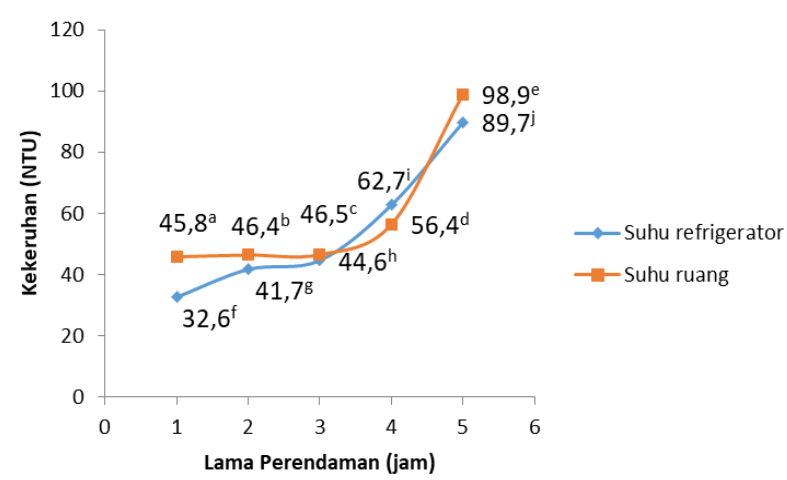

Ket : Notasi huruf yang berbeda menunjukkan peredaan nyata $(p<0,05)$

Gambar 8. Grafik pengaruh suhu dan lama perendaman terhadap kekeruhan

Gambar 8 menunjukkan terdapat perbedaan nyata $(\mathrm{p}=000)$ tingkat kekeruhan pada masing-masing suhu. Kekeruhan pada suhu ruang lebih tinggi dibandingkan kekeruhan pada suhu refrigerator. Hal ini karena pada suhu ruang bahan akan terlarut lebih cepat dibandingkan pada suhu refrigerator. Semakin tinggi suhu maka konstanta kecepatan reaksi akan semakin besar. Peristiwa ini sesuai dengan teori Arrhenius dimana konstanta kecepatan reaksi berbanding lurus dengan suhu (Hok $e t$ al., 2007).

Gambar 8 juga menunjukkan bahwa semakin lama waktu perendaman maka akan semakin banyak bahan yang terlarut sehingga tingkat kekeruhan akan semakin tinggi. Tingkat kekeruhan infused water lemon selama perendaman menunjukkan peningkatan yang berbeda nyata pada masing-masing perendaman $(\mathrm{p}<0,05)$. Hal ini karena selama perendaman proses kelarutan difusi akan terus berlangsung hingga mencapai homogen. Bahan sari buah akan semakin banyak terlarut jika bahan 
semakin lama direndam. Bahan yang terlarut dalam air seperti vitamin khususnya vitamin C dan materi mineral lain yang berasal dari buah. Proses difusi yang terus berlangsung selama perendaman meningkatkan kekeruhan air karena bahan yang terlarut semakin banyak selama perendaman. Menurut Rohmah dan Anton (2008) zat padat seperti garam, mineral, anion, kation yang terlarut didalam air dan berlebih akan meningkatkan kekeruhan air dan menghambat penetrasi sinar ke dalam air. Hal ini serupa dengan penelitian Hardoko et al (2003) yang menyatakan bahwa semakin lama waktu fermentasi maka kekeruhan sari buah akan semakin tinggi.

Hasil analisis sidik ragam menunjukkan bahwa terdapat pengaruh suhu dan lama perendaman terhadap tingkat kekeruhan infused water lemon dan ada pengaruh interaksi suhu dan lama perendaman terhadap tingkat kekeruhan $(\mathrm{p}=0,000)$. Hasil uji lanjut Tukey menunjukkan ada perbedaan nyata pada masing-masing lama perendaman $(\mathrm{p}=0,000)$. Tingkat kekeruhan tertinggi pada suhu ruang dengan lama perendaman 5 jam yaitu sebesar 98,9 NTU dan tingkat kekeruhan terendah pada suhu refrigerator dengan lama perendaman 1 jam yaitu sebesar 32, 6 NTU.

\section{Kadar Vitamin C}

Vitamin C merupakan vitamin yang larut air dan stabil dalam $\mathrm{pH}$ asam. Kelarutan vitamin C dalam air terjadi secara difusi dan menyebar sampai keadaan menjadi homogen. Vitamin $\mathrm{C}$ berpindah dari konsentrasi tinggi ke konsentrasi rendah hingga konsentrasi keduanya menjadi sama. Vitamin $\mathrm{C}$ juga mudah terdegradasi karena suhu panas dan oksidasi (bersentuhan dengan udara). Namun suhu yang tinggi dapat memberikan energi kinetik pada zat sehingga mempercepat laju difusi.

Hasil penelitian infused water lemon menunjukkan bahwa kadar vitamin $\mathrm{C}$ infused water lemon pada perendaman di 
suhu ruang lebih tinggi dibandingkan perendaman di suhu refrigerator. Hasil analisis sidik ragam juga menunjukkan perbedaan nyata pada masing-masing suhu terhadap kadar vitamin $\mathrm{C}(\mathrm{p}=0,000)$. Pada suhu ruang kadar vitamin $\mathrm{C}$ tertinggi sebesar 4,69\% (perendaman 5 jam) dan terendah 3,23\% (perendaman 1 jam). Sedangkan pada suhu refrigerator kadar vitamin $\mathrm{C}$ tertinggi 3,08\% (perendaman 5 jam) dan terendah sebesar 2,35\% (perendaman 1 jam). Kadar vitamin $\mathrm{C}$ dari masing - masing suhu selama perendaman dapat dilihat pada Gambar 9.

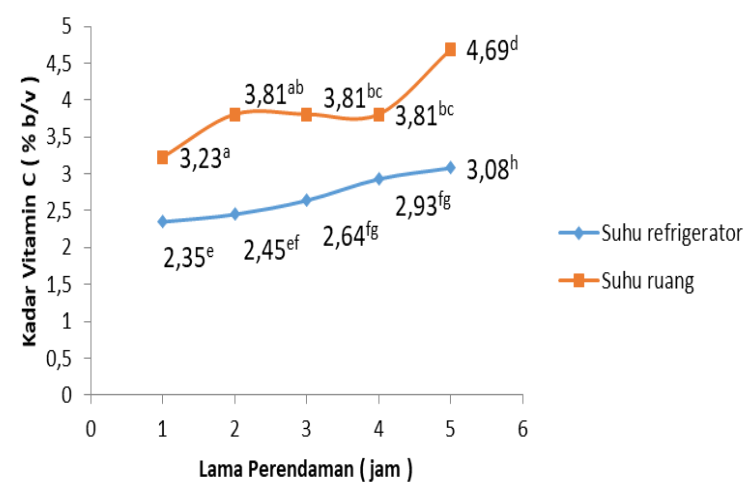

Ket : Notasi huruf yang berbeda menunjukkan peredaan nyata $(p<0,05)$

Gambar 9. Grafik pengaruh suhu dan lama perendaman terhadap kadar vitamin $\mathrm{C}$

Gambar 9 menunjukkan seiring dengan bertambahnya waktu perendaman maka kadar vitamin $\mathrm{C}$ akan semakin meningkat. Hal ini karena selama perendaman vitamin $\mathrm{C}$ akan terlarut dan berdifusi ke dalam air, semakin lama direndam maka vitamin $\mathrm{C}$ akan semakin banyak yang terlarut. Pada awal perendaman yaitu perendaman selama 1 jam, kadar vitamin $\mathrm{C}$ infused water lemon di suhu ruang lebih tinggi daripada di suhu refrigerator. Hal ini berlangsung hingga perendaman selama 5 jam. Menurut Kartika dan Fitri (2015) semakin lama perendaman maka kandungan yang keluar dari dalam bahan akan semakin banyak. Hal ini selaras dengan penelitian Thakur et al (2006) dalam Kartika dan Fitri (2015) yang membuktikan bahwa waktu dan suhu perendaman berpengaruh terhadap larutnya beberapa materi di dalam bahan.

Kadar Vitamin C pada suhu ruang saat perendaman 2 jam, 3 jam, dan 4 jam menunjukkan hasil yang sama yaitu sebesar $3,81 \%$ dan tidak ada berbeda nyata $(\mathrm{p}>0,05)$, 
kemudian mengalami peningkatan yang berbeda nyata $(p=0,007)$ pada perendaman 5 jam. Hal ini diduga karena konsentrasi vitamin $\mathrm{C}$ yang terlarut di dalam infused water lemon mulai menyebar homogen dan mendekati titik jenuh, sehingga kadar vitamin $\mathrm{C}$ menunjukkan hasil yang sama. Sedangkan kadar vitamin C pada suhu refrigerator mengalami peningkatan seiring dengan bertambahnya waktu perendaman walaupun peningkatan yang dialami tidak berbeda nyata pada perendaman 1 jam ke 2 jam $(p=0,074), 2$ jam ke 3 jam $(p=0,979)$, dan 3 jam ke 4 jam $(p=0,795)$. Hal ini menunjukkan bahwa peningkatan kadar vitamin C pada suhu ruang lebih cepat daripada peningkatan pada suhu refrigerator. Fenomena ini sesuai dengan teori Arrhenius yang menyatakan bahwa kecepatan reaksi berbanding lurus dengan suhu. Sehingga semakin tinggi suhu maka perpindahan vitamin $\mathrm{C}$ dari buah ke air akan semakin cepat.
Hasil analisis sidik ragam menunjukkan terdapat perbedaan signifikan kadar vitamin $\mathrm{C}$ pada setiap lama perendaman $(\mathrm{p}=0.000)$. Namun, tidak ada pengaruh interaksi suhu dan lama perendaman terhadap kadar vitamin C $(p=0,053) . \quad$ Uji lanjut Tukey juga menunjukkan adanya perbedaan nyata pada perendaman 1 jam ke 3 jam $(p=0.000), 1$ jam ke 2 jam $(p=0.000)$, dan 1 jam ke 5 jam $(\mathrm{p}=0.000)$. Sehingga dapat disimpulkan bahwa suhu dan lama perendaman berpengaruh terhadap kadar vitamin C infused water lemon.

\section{Aktivitas Antioksidan}

Antioksidan merupakan zat yang mampu meredam radikal bebas dengan cara mendonorkan atom sehingga radikal bebas menjadi bentuk yang stabil. Salah satu kandungan lemon yang mampu berperan menjadi antioksidan adalah vitamin $\mathrm{C}$. Analisis aktivias antioksidan dinyatakan dalam RSA (Radical Scavenging Activity) 
yang didefinisikan sebagai kemampuan antioksidan dalam meredam radikal bebas DPPH. Semakin besar persentase penangkapan radikal maka aktivitas antioksidan semakin besar.

Gambar 10 menunjukkan bahwa ada perbedaan nyata aktivitas antioksidan pada suhu ruang dan suhu refrigerator $(p=0,000)$ namun tidak ada perbedaan nyata pada masing-masing perendaman. Aktivitas antioksidan pada suhu ruang semakin menurun namun semakin meningkat pada suhu refrigerator.

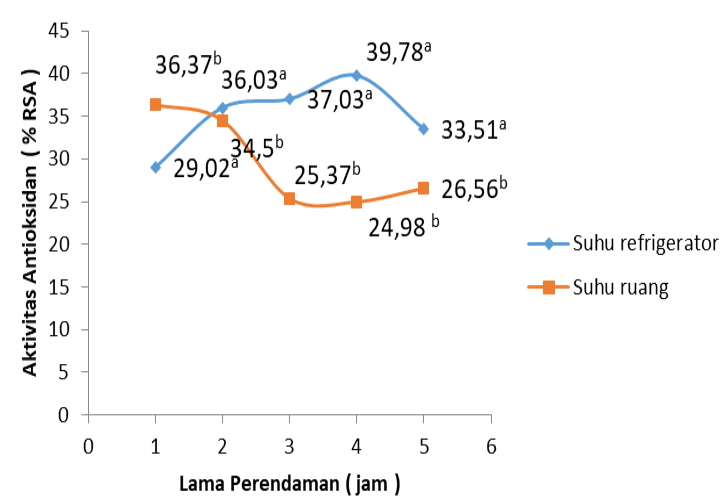

Ket : Notasi huruf yang berbeda menunjukkan peredaan nyata $(p<0,05)$

Gambar 10. Grafik pengaruh suhu dan lama perendaman terhadap aktivitas antioksidan

Hal ini selaras dengan penelitian Dwiyanti dan Hati (2014) yang menunjukkan bahwa aktivitas antioksidan teh rosela semakin menurun selama penyimpanan dalam suhu ruang. Penurunan aktivitas antioksidan infused water lemon pada suhu ruang dimungkinkan karena senyawa antioksidan tidak optimal dalam menstabilkan radikal bebas. Hal ini dimungkinkan karena materi yang terlarut didalam air bukan hanya vitamin $\mathrm{C}$, namun juga materi lain seperti asam sitrat, flavonoid, total fenol dan mineral lain. Banyaknya materi yang terlarut membuat vitamin $\mathrm{C}$ yang berperan sebagai antioksidan tidak stabil. Selain itu, senyawa antioksidan lain seperti total fenol dan flavonoid juga terlarut di dalam air dan meningkatkan konsentrasi aktivitas antioksidan didalam air. Hal lain yang dimungkinkan terjadi yaitu seyawa telah bersifat prooksidan karena tingginya konsentrasi antioksidan didalamnya. Menurut Sayuti dan Rina (2015) asam askorbat atau vitamin $\mathrm{C}$ dapat bersifat menjadi prooksidan. 

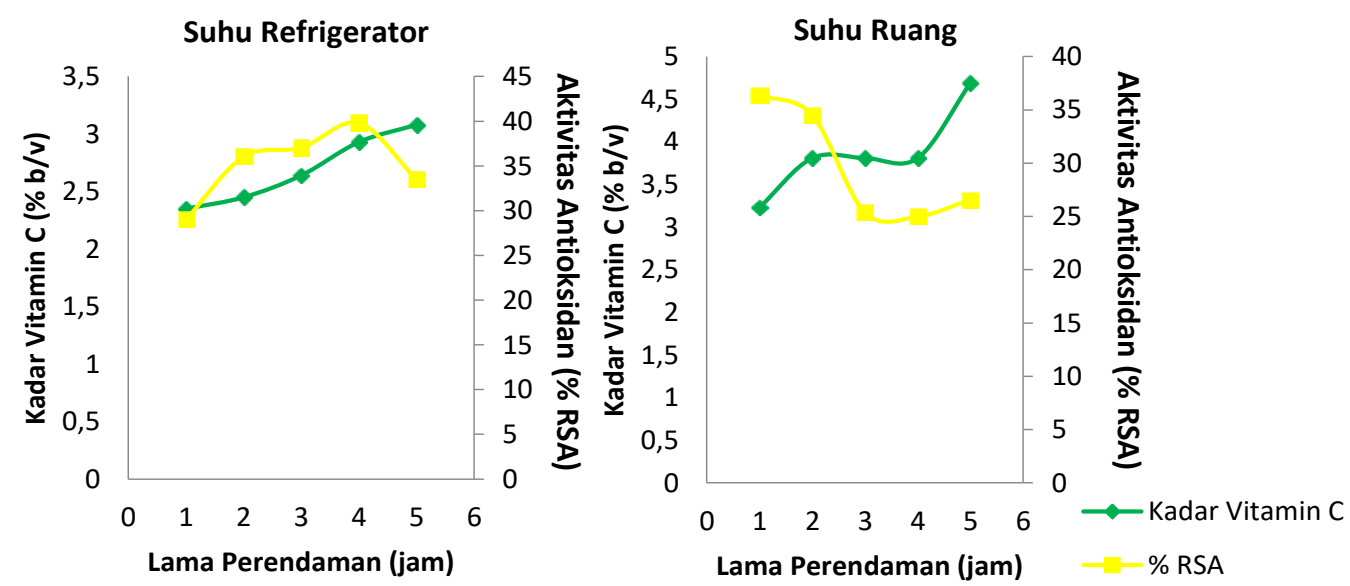

Gambar 11. Grafik hubungan kadar vitamin C dan aktivitas antioksidan infused water lemon

Gambar 11 menunjukkan kadar

vitamin $\mathrm{C}$ suhu ruang yang stabil pada perendaman 2, 3, dan 4 jam dan mulai naik pada perendaman 5 jam, dan aktivitas antioksian yang semakin menurun. Menurut Gordon (1990) dalam Kadji dan Gayatri (2013) besar konsentrasi antioksidan yang bertambah (konsentrasi tinggi) dapat berpengaruh pada laju oksidasi. Pada konsentrasi tinggi, aktivitas antioksidan grup fenolik sering lenyap bahkan antioksidan tersebut berubah menjadi prooksidan. Berikut adalah reaksi antioksidan yang bertindak sebagai prooksidan pada konsentrasi tinggi (Siti, 2009) :

$\mathrm{AH}+\mathrm{O}_{2} \rightarrow \mathrm{A}^{*}+\mathrm{HOO}^{*}$

$$
\mathrm{AH}+\mathrm{ROOH} \rightarrow \mathrm{RO}^{*}+\mathrm{H}_{2} \mathrm{O}+\mathrm{A}^{*}
$$

Sementara itu, infused water lemon pada suhu refrigerator menunjukkan korelasi yang selaras antara vitamin $\mathrm{C}$ dan aktivitas antioksidan. Semakin tinggi kadar vitamin C maka aktivitas antioksidan semakin naik. Laju difusi yang lebih lambat pada suhu refrigerator membuat kadar vitamin $\mathrm{C}$ bertambah secara perlahan hingga perendaman 4 jam dan mencapai konsentrasi optimum pada perendaman 5 jam.

Hasil analisis sidik ragam menunjukkan terdapat perbedaan signifikan aktivitas antioksidan pada suhu refrigerator dan suhu ruang $(\mathrm{p}=0.000)$ namun tidak terdapat perbedaan signifikan aktivitas 
antioksidan pada setiap lama perendaman $(\mathrm{p}=0.094)$. Selain itu, terdapat pengaruh interaksi antara suhu dan lama perendaman terhadap aktivitas antioksidan $(\mathrm{p}=0.000)$. Semakin tinggi suhu dan semakin lama perendaman maka aktivitas antioksidan akan semakin naik hingga mencapai titik konstan. Perlakuan terbaik untuk mendapatkan kandungan vitamin $\mathrm{C}$ dan aktivitas antioksidan optimum yaitu perendaman 1 jam pada suhu ruang atau perendaman 4 jam pada suhu refrigerator.

\section{DAFTAR PUSTAKA}

Anggraeni, A. 2011. Kelarutan Sebagai Fungsi Suhu. (Laporan Kimia Fisika). Institut Teknologi Bandung, Bandung.

Dwiyanti, G. dan Hati N.K. 2014. Aktivitas Antioksidan Teh Rosela (Hibiscus sabdariffa) Selama Penyimpanan Pada Suhu Ruang. Prosiding Seminar Nasional Sains UKSW Vol 5 No 1.

Faramade, OO., 2007. Kinetics of Ascorbic Acid Degradation in Commercial Orange Juice Produced Locally in Nigeria. African Crop Science Conference Proceedings. 8 : 1813 1816.
Hardoko, Adolf P. dan Ivonne PK. 2003. Mempelajari Karakteriktik Sari Buah dari Mengkudu (Morindra citrifolia Linn.) yang Dihasilkan Melalui Fermentasi. Jurnal Tekno dan Industri Pangan Vol XIV No. 2 : $144-153$.

Haitami, Annisa U., dan Akhmad M. 2017. Kadar Vitamin C Jeruk Sunkish Peras dan Infused Water. Medical Laboratory Technologi Journal 3 (1), 98 - 102. Poltekkes Kemeskes Banjarmasin.

Hok, KT, Wiwit S.,Wenny E., dan Felicya ES. 2007. Pengaruh Suhu dan Waktu Pemanasan Terhadap Kandungan Vitamin A dan C Pada Proses Pembuatan Pasta Tomat. Widya Teknik Vol 6 No.2 (111120).

Kadji, M.H., Max R.J.R., Gayatri C. 2013. Uji Fitokimia dan Aktivitas Antioksidan dari Ekstrak Etanol Daun Soyogik. Jurnnal Farmasi : FMIPA UNSRAT Manado.

Kartika, P.N dan Fithri C.N. 2015. Pembuatan Osmodehidrat Buah Nanas (Ananas comosus L. Merr) : Kajian Konsentrasi Gula Dalam Larutan Osmosis dan Lama Perendaman . Jurnal Pangan dan Agroindustri Vol. 3 No 4 p.13451355.

Krisnawan, AH, Ryanto B., Devi R.,Weilinten S. 2017. Potensi Antioksidan Ekstrak Kulit dan Perasan Daging Buah Lemon (Citrus Lemon) Lokal dan Impor. Prosiding Seminar Nasional 2017 Fakultas Pertanian UMJ. 
Kristanto, F. 2013. Kekerasan Permukaan Enamel Gigi Manusia Setelah Kontak dengan Air Perasan Citrus Limon. (Skripsi). Universitas Airlangga, Surabaya.

Permata, AN, Atik K. dan Betty L. 2018. Screening Fitokimia, Aktivitas Antioksidan dan Antimikroba Pada Buah Jeruk Lemon (Citrus limon) dan Jeruk Nipis (Citrus aurantiifolia). Jurnal Ilmiah Ibnu Sina, 3(1), 64-76.

Rohmah, N. dan Anto T.S. 2008. Peurunan TS (Total Solid) Pada Limah Cair Industri Perminyakan Dengan Teknologi AOP. Pusat Penelitian Lembaga Ilmu Pengetahuan Indonesia, Bandung.

Romain, MGS. 2014. Alat Pendeteksi

Kekeruhan Air Menggunakan Parameter Fisika Berbasis Mikrokontroller Aymega8535. (Laporan Akhir). Politeknik Negeri Sriwijaya, Palembang.

Sapei, L. dan Lie H. 2014. Study on The Kinetics of Vitamin C Degradation in Fresh Strawberry Juice. Jurnal Procedia Chemistry 9: 62-68.

Sayuti, K. dan Rina Y. 2015. Antioksidan Alami dan Sintetik. Andalas University Press, Padang.

Soraya, N. 2014. Infused Water. Penerbit Penebar Swadaya, Jakarta.

Sudarmaji, S. 1989. Analisa Bahan Makanan dan Pertanian. Penerbit Lyberty, Yogyakarta.

Wassalwa, M., 2016. Pengaruh Waktu Infusa dan Suhu Air yang Berbeda Terhadap Aktivitas Antioksidan dan Vitamin C pada Infused Water Kulit Pisang. Jurnal Ilmiah Mahasiswa : Universitas Syiah Kuala. 